\title{
Perceptions of nutrition education classes offered in conjunction with a community-supported agriculture intervention among low-income families
}

\author{
Isabel Lu ${ }^{1}$, Karla L Hanson², Stephanie B Jilcott Pitts ${ }^{3}$, Jane Kolodinsky4, \\ Alice S Ammerman ${ }^{5}$, Marilyn Sitaker ${ }^{6}$, Weiwei Wang ${ }^{6}$, Leah C Volpe', \\ Emily $\mathrm{H}_{\text {Belarmino }}{ }^{1}$ (i) , Jennifer Garner ${ }^{8}$ (i), Liana Gonsalves ${ }^{1}$ and \\ Rebecca A Seguin $9,10, *$ \\ 'Division of Nutritional Sciences, Cornell University, Ithaca, NY, USA: ${ }^{2}$ Master of Public Health Program, Department \\ of Population Medicine and Diagnostic Sciences, Cornell University, lthaca, NY, USA: ${ }^{3}$ Department of Public Health, \\ Brody School of Medicine, East Carolina University, Greenville, NC, USA: ${ }^{4}$ Department of Community Development \\ and Applied Economics, University of Vermont, Burlington, VT, USA: ${ }^{5}$ Center for Health Promotion and Disease \\ Prevention, University of North Carolina at Chapel Hill, Chapel Hill, NC, USA: ${ }^{6}$ Ecological Agriculture and Food \\ Systems, The Evergreen State College, Olympia, WA, USA: ' Department of Nutrition and Food Sciences, University of \\ Vermont, Burlington, VT, USA: ${ }^{8}$ School of Health and Rehabilitation Sciences, Ohio State University, Columbus, OH, \\ USA: ${ }^{9}$ Agrilife Research, Texas A\&M University, College Station, TX, USA: ${ }^{10}$ Department of Nutrition, College of \\ Agriculture and Life Sciences, Texas A\&M University, College Station, TX, USA
}

Submitted 30 January 2020: Final revision received 24 June 2020: Accepted 8 July 2020: First published online 24 August 2020

\begin{abstract}
Objective: To examine participants' experiences with nutrition education classes that were implemented with and designed to complement a cost-offset community-supported agriculture (CSA) programme.

Design: Qualitative analysis of data from twenty-eight focus groups with ninety-six participants enrolled in Farm Fresh Foods for Healthy Kids (F3HK). Transcribed data were coded and analysed by a priori and emergent themes.

Setting: Rural and micropolitan communities in New York, North Carolina, Vermont and Washington (USA).

Participants: Ninety-six F3HK participants.

Results: Participants found recipes and class activities helpful and reported improvements in nutrition knowledge, food preservation skills and home cooking behaviours for themselves and their children; they also reported that classes promoted a sense of community. Some educators better incorporated CSA produce into lessons, which participants reported as beneficial. Other obligations and class logistics were barriers to attendance; participants recommended that lessons be offered multiple times weekly at different times of day. Other suggestions included lengthening class duration to encourage social engagement; emphasising recipes to incorporate that week's CSA produce and pantry staples and offering additional strategies to incorporate children in classes.

Conclusion: Complementing a cost-offset CSA with nutrition education may enhance programme benefits to low-income families by improving nutrition knowledge and cooking behaviours. However, future interventions will benefit from ongoing coordination between educators and local growing trajectories to maximise timely coverage of unfamiliar produce in lessons; synchronous scheduling of CSA pick-up and classes for participant convenience and creative strategies to engage children and/or provide childcare.
\end{abstract}

Keywords

Community-Supported Agriculture (CSA)

Nutrition education

Cooperative extension

Local food

Vegetable consumption 
Diets rich in fruits and vegetables reduce risk of heart disease $^{(1,2)}$, some cancers ${ }^{(1,3)}$, diabetes ${ }^{(4,5)}$ and all-cause mortality ${ }^{(6)}$. Although the overall US population is underconsuming fruits and vegetables, low-income individuals consume even less ${ }^{(7)}$ and also have greater risk of chronic diseases $^{(8)}$ and all-cause mortality ${ }^{(9)}$. Greater risk of dietrelated chronic disease among low-income individuals may be partially attributed to lower nutrition knowledge ${ }^{(10)}$ and limited cooking skills ${ }^{(11)}$.

Community-supported agriculture (CSA) and other direct-to-consumer models may be a unique way to address limited nutrition knowledge and access to healthy food among low-income populations. The CSA model, brought to the USA in the 1980s from Switzerland and Japan $^{(12)}$, is characterised by an economic partnership between farmers and consumers, in which consumers purchase a 'share' of a farm's crop prior to the growing season and receive portions of the produce grown ${ }^{(13)}$. CSA farms can be found in all regions of the $\mathrm{USA}^{(12,14)}$. In 2015, 7398 farms sold $\$ 226$ million in product through CSA sales ${ }^{(15)}$ and membership has increased in the past 15 years $^{(14)}$. CSA members tend to be higher income and well educated ${ }^{(16,17)}$, and cost is a major barrier to participation ${ }^{(18)}$. However, CSA are associated with higher fruit and vegetable consumption ${ }^{(19-21)}$, and participation among low-income families may promote produce intake and adoption of healthy eating patterns ${ }^{(20,22)}$.

A major barrier to use of CSA produce is lack of education or experience with proper preparation methods ${ }^{(23)}$. While it is imperative that interventions aiming to improve fruit and vegetable consumption among low-income populations provide the skills and knowledge needed to support behaviour change, several barriers exist in implementing nutrition education to these communities. Such barriers include transportation challenges, a lack of reinforcing infrastructure and educators seen as 'outsiders' ${ }^{\text {(24) }}$. Perceived benefits of and barriers to attending CSA-paired nutrition education classes among lowincome families have been reported by Quandt et al. ${ }^{(20)}$. Quandt et al. found barriers to be conflicting family activities and night classes, as well as frequently changing contact information. Recommendations for improvement were to partner with agencies and hold nutrition education classes at natural hubs for families ${ }^{(20)}$. However, the current literature still lacks dedicated exploration into the experiences of participants enrolled in CSA-paired nutrition education and the potential benefits.

Farm Fresh Foods for Healthy Kids (F3HK) was a randomised intervention trial for low-income families and their children. The trial partnered with twelve farms across four states - New York, Vermont, Washington and North Carolina - to implement a subsidised or 'cost-offset' community-supported agriculture (CO-CSA) programme paired with nutrition education. Participating farms were selected by community partner referrals. We sought farms who accepted, or were willing to accept, Supplemental
Nutrition Assistance Program benefits; were willing to offer weekly payment plans for participants and who agreed to participate in a sustainability plan to continue the CO-CSA programme after the intervention's conclusion. Participants agreed to pay $50 \%$ of the CSA share and the remaining $50 \%$ was paid upfront to farms by study grant funds. The goal of F3HK was to investigate the effects of the intervention on diet, other health behaviours and local economies. Participants were randomised into the intervention or the delayed intervention control group. Participants of the intervention group received the CO-CSA and CSA-tailored nutrition education in 2016, and the delayed intervention control received the same intervention one year later in 2017.

After completion of a full season of the intervention, participants were invited to take part in focus group discussions to share their experiences with the CSA programme and nutrition education classes. The present paper aims to describe: (1) participants' experiences with nutrition education classes; (2) barriers to attending education classes; (3) similarities or differences in perceived barriers between those who attended at least one class and those who did not attend any classes and (4) recommendations to improve class curricula and reduce barriers to attendance.

\section{Methods}

\section{Education curriculum}

The education curriculum was developed to align with locally grown produce items and state agricultural calendars $^{(25-31)}$ and with input from an advisory committee which included researchers and Cooperative Extension education representatives from each of the four states. The overall objectives of the nutrition education were to (1) address attitudes and beliefs about the value of consuming fruits and vegetables (outcome expectation); (2) improve skills and self-efficacy with respect to storing, preparing and consuming CSA produce (self-efficacy); (3) reduce potential barriers to acceptance of CSA produce and develop strategies to substitute fruits and vegetables for more energy-dense, nutrient-poor foods (barriers); (4) increase skills and self-efficacy related to preparation of CSA produce using minimal solid fat and sugar (behavioural capacity); (5) provide opportunities for participants to observe peers demonstrating newly acquired skills and share new experiences via group discussion (observational learning/modelling) and (6) provide information and strategies to help families be more active in daily life and reduce sedentary time, particularly screen time. Each farm site had nine classes that were provided during the CSA season which varied from 15 to 24 weeks. Educators completed a two-hour, web-based training on the curriculum's organisation and content, as well as best practices for educating adults. They were encouraged to hold three classes at the 
beginning of the season, three classes mid-season and three classes near the end of the season. Most classes included an 'apply' activity that involved hands-on food preparation aimed to stimulate behaviour change in fruit and vegetable intake ${ }^{(32,33)}$. Tastings did occur, but full meals were not typically provided. While lessons focused on adults, each class included child-friendly activity adaptations and materials. More details on the design and methods of the F3HK intervention have been published by Seguin et al. ${ }^{(34)}$

The nine-lesson curriculum was implemented in each farm community during the CSA season which varied from 15 to 24 weeks. Educators were encouraged to hold three classes at the beginning of the season, three classes midseason and three classes near the end of the season. Drawing on prior research about barriers to participation in CSA-tailored education ${ }^{(20)}$, many classes were held at natural hubs for family activities that included churches, schools, a community centre, an extension office and one of our CSA farms. In addition, research staff queried participants about convenient days and times for lessons, and educators scheduled classes to accommodate the greatest number of participants.

\section{Recruitment and focus groups}

We recruited focus group participants from families that participated in the F3HK intervention. We contacted F3HK participants via email, phone and text message to participate at the end of the first season of CSA membership (2016 for intervention participants and 2017 for delayed intervention participants). Adhering to the trial's inclusion criteria, all participants were parents or legal guardians of one or more children aged 2-12 years. Those who had participated in a CSA in the past 3 years were excluded. Participants were asked for their annual household income. Participants who could not attend the scheduled focus group in 2016 were invited to the 2017 focus group. We asked participants to share their experiences with the intervention, including how the CSA share and education classes may have impacted at-home behaviours. In 2016, we held fourteen focus groups in November and December with a total of fifty-three attendees. In the second year of implementation, we held a further fourteen groups between September and December with a total of forty-three attendees. We held at least one focus group for each of the twelve farm sites each year. Attendance at each focus group ranged from one to eight participants. Focus group discussions lasted 60-90 min, were held in community locations and were facilitated by a trained interviewer. Prior to the groups, we conducted a facilitator training to review how to establish a welcoming atmosphere, remain neutral, ask effective probes and manage group dynamics. Participants provided written consent prior to the start of each focus group. We allowed caregivers to bring their children but did not provide formal childcare.
Each participant was compensated $\$ 25$. Some participants did not attend any classes but were still invited to attend a focus group and asked to speak on their personal barriers to attendance. On average, focus group participants attended 4.17 classes, ranging from 0 to 9 , out of a total of nine classes. Sixteen did not attend any F3HK nutrition education classes.

We developed a semi-structured discussion guide with two parts. First, we assessed CSA access modelled on the $5 \mathrm{~A}$ framework for access which was adapted by Caspi et al. to be specific to food access. Dimensions included availability, accessibility, affordability, acceptability and accommodation $^{(35)}$. Findings from this discussion have been reported by White et al. ${ }^{(36)}$

Second, we inquired about participants' experiences with, and perceptions of, the education classes themselves. The current paper focuses on description and analysis of these experiences and perceptions.

\section{Qualitative analysis}

We audio recorded the focus groups and transcribed them verbatim before uploading into Nvivo Pro version 11 (QSR International) for data management and coding. We developed an initial inductive codebook based on the questioning structure of the discussion guide. Two researchers (I.L. and L.G.) independently coded four transcripts. A third researcher (L.C.V.), who led focus group facilitation in New York, joined the other two researchers and together the team reviewed the initial coding, discussed and resolved discrepancies and developed new codes based on emergent ideas. Based on these discussions, we revised the codebook and used this revised version to recode the four transcripts and all remaining transcripts. All coding took place between March and May 2019. Inter-coder reliability was high, with observed agreement $>99 \%$ and prevalence-adjusted and bias-adjusted kappa $>99 \%$. Given the high level of agreement between coded files, we analysed the data using the first author's coding. Our analysis involved reviewing each code and summarising ideas presented. We organised the analysis in three categories: benefits of classes, barriers to class attendance and recommendations for improving classes. Themes presented in the results were drawn from each of the four participating states.

\section{Results}

Almost all participants were female and over $60 \%$ had an annual household income of less than \$US 35000 (Table 1). We report findings according to the objectives and illustrate dominant and recurring themes with quotations.

\section{Perceived class benefits}

Participants described seven major benefits of class attendance: recipe ideas, caregiver cooking and food 
Table 1 Demographic data for focus group adults with children ( $n$ 96) Participating in the farm fresh foods for healthy kids (F3HK) multicentre randomised intervention trial's cost-offset communitysupported agriculture (CO-CSA) programme. Focus groups were held in 2016 and 2017 and were located in nine communities in New York, North Carolina, Washington and Vermont states

\begin{tabular}{|c|c|c|c|c|}
\hline \multirow[b]{2}{*}{ Characteristics } & \multicolumn{2}{|c|}{2016} & \multicolumn{2}{|c|}{2017} \\
\hline & $n$ & $\%$ & $n$ & $\%$ \\
\hline \multicolumn{5}{|l|}{ Participant age } \\
\hline Mean & 37.5 & & 38.4 & \\
\hline $\mathrm{SD}$ & $8 \cdot 3$ & & $7 \cdot 8$ & \\
\hline \multicolumn{5}{|l|}{ Child age } \\
\hline Mean & 6.5 & & 5.9 & \\
\hline SD & $3 \cdot 2$ & & $2 \cdot 9$ & \\
\hline \multicolumn{5}{|l|}{ Location of CSA farm } \\
\hline New York & 25 & 47 & 17 & 40 \\
\hline North Carolina & 17 & 32 & 12 & 28 \\
\hline Washington & 3 & 6 & 7 & 16 \\
\hline Vermont & 8 & 15 & 7 & 16 \\
\hline Female & 50 & 94 & 42 & 97 \\
\hline \multicolumn{5}{|l|}{ Race and ethnicity } \\
\hline Black & 10 & 19 & 7 & 16 \\
\hline White, Non-Hispanic & 34 & 64 & 29 & 68 \\
\hline Other or unknown & 9 & 17 & 7 & 16 \\
\hline \multicolumn{5}{|l|}{ Number of children at home } \\
\hline 1 & 15 & 28 & 11 & 26 \\
\hline 2 & 19 & 36 & 20 & 47 \\
\hline 3 & 9 & 17 & 10 & 23 \\
\hline 4 or more & 10 & 19 & 2 & 4 \\
\hline \multicolumn{5}{|l|}{ Employment status } \\
\hline Employed & 24 & 45 & 21 & 49 \\
\hline Unemployed, student or retired & 6 & 11 & 7 & 16 \\
\hline Homemaker & 23 & 43 & 15 & 35 \\
\hline \multicolumn{5}{|l|}{ Annual household income } \\
\hline Less than \$US 20000 & 17 & 33 & 10 & 24 \\
\hline \$US 20 000-34 999 & 18 & 34 & 15 & 36 \\
\hline \$US $35000-49999$ & 14 & 27 & 13 & 31 \\
\hline \$US 50 000-74 999 & 3 & 6 & 4 & 9 \\
\hline
\end{tabular}

preservation skills, caregiver nutrition knowledge, improved home cooking behaviours, child knowledge and skills, sense of community and enhanced CSA experience.

\section{Recipe ideas}

Participants reported the primary benefit of the classes to be the distribution of recipes. Most participants reported that recipes helped them learn to cook unfamiliar produce and introduced different and new ways to prepare familiar vegetables. The recipes were even beneficial to those who could not attend classes; some educators emailed participants recipes in addition to handing them out in class.

'It [the class] gave you ideas to cook with some of the [CSA] stuff ... that we didn't know how to cook.' (NC, Farm 31)

I think it was most helpful that we got recipes of things that were cooked in the class, so if we missed it we could try it at home.' (NC, Farm 32)

I cook radishes now [laughter], um I think I use more herbs too... because a lot of the recipes you use fresh herbs in the book that they gave us and some of the cooking classes.' (VT, Farm 41)
Caregiver cooking and food preservation skills

Class activities were also helpful, as many participants reported that they learned cooking techniques such as stir-frying, steaming and chopping. Participants also noted that they learned food preservation techniques like freezing produce and drying herbs and that they felt more confident in the kitchen and cooked more at home.

'Learning the different ways to steam things ... it did give me ideas with ways to prepare certain things' (NY, Farm 13)

'Taught me how to make more stir fries like how to really incorporate more vegetables into a stir fry' (NY, Farm 13)

I learned ... how to cut properly. There's a way that you're supposed to cut things ... there's different cooking techniques, and then also how to preserve your ... veggies for longer, and stuff like that.' (VT, Farm 44)

Perceived caregiver nutrition knowledge

Many participants appreciated the activities that took place outside of the kitchen and described learning new skills and knowledge that complemented their CSA experience. For example, the grocery store tour covered calculating price based on weight and helped participants recognise cost differences based on unit price rather than sale price. Participants described how the visualisation exercises helped them understand the health risks associated with popular dishes that their families may consume when not eating at home.

'The unitprice $v$. the sale ... and then you know how to compare, that was very helpful... to see if you're actually getting a sale.' (NC, Farm 32)

"So you picked the Denny's Grand Slam and she gave you a hamburger bun and a tub of lard and said, "Okay that Grand Slam equals"... 8 scoops of lard and just visualizing it" (NY, Farm 12)

Home cooking behaviours

Several participants described cooking and eating more vegetables as a result of the cooking classes. They said classes encouraged them to cook more and to use healthier cooking techniques. Many stated feeling more confident in the kitchen and were more willing to involve their children in the kitchen at home after the cooking classes.

II think it opened me up to a different mindset on looking at vegetables ... This way I realize "yeah, it doesn't take that much to cook it, or bake it or fry it.".' (WA, Farm 22)

'Cooking is kind of a stressful thing for me. I was always brought up, you know, one person in the kitchen. So I've actually learned to let the kids do things and make a mess and not be so stressed about it.' (NY, Farm 11) 
'I use less oil... and I try to use bealthier oil like... olive oil, avocado oil.' (NY, Farm 11)

\section{Perceived child knowledge and skills}

Instructors also endeavoured to engage children in activities, such as colouring a diagram of MyPlate, and in cooking preparation, such as allowing them to cut vegetables and help clean up. Many participants reported that children found the classes to be fun and looked forward to helping to cook each week. Some parents noted that this enthusiasm translated into greater interest among their children to help cooking at home.

'Yeah, [the educator] was really good about having her [my daughter] do things, you know, that she could do. Like chopping certain things or washing things or stirring.' (VT, Farm 41)

'Definitely made them want to be more involved at bome. My kids want to belp cook now.' (NC, Farm 32)

Sense of community

Many participants felt a sense of community with other attendees, the instructors and the children. They noted how classes and open discussions facilitated sharing of recipes and cooking ideas and how cooking together and sharing meals reinforced a sense of comradery. Conversations during classes were described as 'fun', and participants exchanged contacts and made friends. Some participates noted that their children made friends with other participants' children.

'It was awesome. She [daughter] got to participate and that was one of my favorite things, having the community aspect of the classes because it makes the bealthy food really important when we are actually gathering in one space together to share and cook a meal together.' (WA, Farm 22)

\section{Enhancement of the community-supported agriculture experience}

Some participants reported that classes supported their CSA experience through discussions of how to use the weekly produce. However, this was only discussed at three locations. Participants at seven locations suggested that class lessons and recipes be more focused on the produce they received in their CSA shares.

'So that was really a key to this program, was the Thursday [CSA pick-up] and the Thursday night we had the cooking, and it was the same exact thing that was in our bag. It was really nice.' (NC, Farm 32)

'One time I asked bey, can we figure out what to do with koblrabi cause I'm so lost... can we do some recipes or something.' (NC, Farm 32)

\section{Barriers to class attendance}

Participants discussed three major barriers to class attendance: personal obligations, caretaker obligations and class logistics. We did not observe notable differences in the types of barriers between participants who attended one or more classes and those who could not attend any.

\section{Personal obligations}

Most participants who did not attend any of the education classes reported work and school obligations to be important barriers to attending classes. Many of these participants described that education classes offered in the middle of the day were particularly difficult to attend due to work, and a few mentioned how education classes conflicted with their night college classes.

'We would have loved to have done the cooking classes, but I couldn't. I got a new job. So schedule-wise I've been working a lot of hours.' (NY, Farm 12)

'I wasn't able to make any of the classes because I was working.' (WA, Farm 23)

\section{Caregiver obligations}

Participants described prioritising family obligations over nutrition education classes. Among those with small children and infants, evening class times interfered with early bedtimes.

Participants with older children juggled multiple extracurricular activities after school, such as sports practices and afterschool education programmes.

'It was hard for me because I have some [kids] in sports practice, [as a] single parent, I had to be the one to pick up and that time is around dinner time and close to time they get out of practice. So just that little group after, the little cooking class, I really had trouble sticking with that.' (NC, Farm 32)

Early evening classes also made dinner preparations late and rushed, leaving some participants forced to order take-out or skip dinner to rush to class right after work. And although participants often sampled dishes they cooked during class, many thought that the dishes were not substantial enough for a meal and reported feeling hungry and tired during and after class.

'Yeah it was ... you know by the time [husband] got out of work and we got here we didn't have time to cook dinner.' (NY, Farm 12)

'I was usually already hungry when I got there, and I'm like, I wanna hurry up and, you know, get this done so I can eat! Um, but then at the same time it usually was not very filling, and so when I got home, I was still wanting something to eat. But it was like 7:30, almost 8 o'clock. Um, so that was kind of hard to deal with.' (NC, Farm 32)

Class logistics

Differences in class logistics also affected coordination between CSA pick-up and class times and dates. At five locations, educators scheduled classes to correspond with 
CSA pick-up times and locations. Participants at these sites reported this to be convenient and said they appreciated maximising their travel time in this way. For others, the distance between their home and the class location and the lack of coordination with CSA pick-up were problematic.

'The classes were on... was it Tuesday or Wednesday? And then pickup was on Thursday and I'm like [long pause] I'm driving to [town] twice a week. So that made my commute harder.' (NY, Farm 12)

\section{Recommended class improvements}

Participants made four distinct suggestions for improving the F3HK education classes: offer multiple classes a week, lengthen the class time, make greater use of the CSA produce in the class activities and provide childcare.

Multiple classes a week

Participants offered suggestions to resolve conflicts with work and personal schedules. However, opinions varied on whether classes should be held on weekends or weekdays. Participants suggested repeating the class lesson more than once a week, on different days and at different times:

'It would have been nice if they were not always on the same day of the week so that if a participant can never do a Wednesday, at least there is one day that they will be able to do. Or maybe gather the availability of participants in general and then based on that pick two different days that work for most people.'

(WA, Farm 22)

Lengthen the class time

Participants recommended extending classes from 60 to 90 or $120 \mathrm{~min}$. Many felt that classes were rushed, especially when they were involved in cooking activities and socialisation. Several participants suggested that eating and socialising should be included in an extended class period so that sufficient time could be given to the curriculum and activities and extra time at the end could serve as a 'buffer' for community building.

'I think the class should be scheduled for an hour and a half because really the last 15 minutes was eating the food and coming back together as a community. So having that scheduled into the class time so that we didn't have to rush off . . having an extra buffer of time, having that scheduled in.' (WA, Farm 22)

Greater use of community-supported agriculture produce and pantry staples

Participants strongly suggested that cooking classes focus more explicitly on the produce included in the weekly CSA share. Additionally, demonstrating recipes that only required pantry staples in addition to CSA items was important. As one participant explained:
'. . we were making something that I would have to go buy all the ingredients on top of the CSA. So I was like this is not okay for me. For me I thought it was going to be like a cooking class for adults where you go and use the things from your box to make.' (NY, Farm 11)

\section{Providing childcare}

Some participants with small children reported that providing childcare would have been a significant incentive for attendance. Although children were welcome to attend, these caregivers raised concerns over children being distracting or not sufficiently accommodated in classes and suggested incorporating more structured activities for children so the adults could focus on the class content. Although the curriculum outlined ways to involve children in some discussions and cooking activities, young children were often left unoccupied.

'...my other two girls were not as excited cause they're a little younger. I think standing there for a long time was a little challenging for them.' (NY, Farm 13)

'Yeah, they got antsy because they got bored. If you have some kind of organized activity for the kids while we were doing our portion, I think would've been great.' (VT, Farm 44)

\section{Discussion}

This qualitative study of low-income participants in a COCSA intervention investigated participants' perceived experiences of nutrition education classes, barriers to class attendance and recommendations for class improvements. Some of the findings align with previous evaluations of nutrition education classes. To our knowledge, this is only the second peer-reviewed paper to examine perceptions of nutrition education designed to complement cost-offset CSA programmes, and our findings generally are consistent with that smaller study ${ }^{(20)}$. Below we highlight several unique findings, including those that may help to inform future interventions with similar goals and target populations.

Participants described five benefits of the education classes that aligned with prior research: recipe ideas, caregiver cooking and food preservation skills, improved perceived child knowledge and skills, perceived caregiver nutrition knowledge and improved home cooking behaviours. Our findings are congruent with other studies that find recipes and cooking lessons to be effective in helping low-income families enhance their cooking skills ${ }^{(37,38)}$ and added support for the inclusion of food preservation among the food preparation skills taught. Perceived changes to children's knowledge and skills as a result of nutrition and cooking education also align with prior research ${ }^{(39)}$. Non-cooking activities, such as a grocery store 
tour and food content visualisations, contributed to perceived increases in caregiver nutrition knowledge. Grocery store tours have been shown to improve knowledge and intention to consume more fruits and vegetables $^{(40,41)}$ and are widely used in healthy eating promotion programmes ${ }^{(38,42)}$ such as Supplemental Nutrition Assistance Program-Ed ${ }^{(43)}$.

Participants also noted two benefits not reported in prior research: a sense of community and an enhanced CSA experience. There was a sense of community with other participants and the instructors, especially around open discussion of their CSA experience and sharing food. Sharing meals after cooking lessons may have contributed to social bonding, which makes individuals feel better about themselves and closer to those around them ${ }^{(44)}$. To our knowledge, no other study has reported social eating as a benefit to cooking classes and nutrition education. Future interventions should consider the inclusion of community bonding activities for participant enjoyment and retention.

The perception that cooking and tasting activities enhanced the CSA experience was only reported as a benefit by participants at three locations where educators incorporated the current week's CSA produce into the class lesson and featured recipes. Although class content had been developed to align with locally grown produce items and state agricultural calendars ${ }^{(25-31)}$, recipes did not always use items in the participant CSA share for that week. Dannefer et al. showed that pairing nutrition education with shopping at a farmers' market increases willingness to try new fruits and vegetables ${ }^{(45)}$. Acceptability of introducing new foods from the CSA shares to their families was a focus group theme ${ }^{(36)}$; thus, it would be beneficial for educators to have knowledge and access of specific weekly CSA contents to highlight the produce in class activities. To this end, F3HK educators were offered CSA shares alongside participants during the second year of the intervention (2017). Even with this change, featured produce sometimes differed from participants' share contents either because class participants received shares from different farms or the share contents differed within the same farm, preventing perfect alignment with lesson content and requiring educators to adapt lessons with little notice. However, direct, advance coordination between educators and farmers may not be realistic given farmers' chaotic schedules and the unpredictability of the growing season. Educators' use of passive means (e.g. farm newsletters or social media) may be another mechanism by which to improve coordination. Future studies should explore strategies for improved coordination and for bolstering consumers' adaptability to the flexible shopping and cooking routines required when relying on the local food system.

Participants reported conflicting work and family obligations as primary challenges to class attendance, citing work schedules, night classes and children's extracurricular activities as examples. Accommodating different schedules and finding a class time that worked for all participants was a major theme for Slusser et al. ${ }^{(46)}$ Quandt et al. previously reported on barriers to low-income participants' attendance at educational sessions paired with a CSA programme and found similar challenges ${ }^{(20)}$. We sought to overcome barriers identified by Quandt et al. regarding conflicting family activities and scheduling ${ }^{(20)}$ by surveying families to identify preferred class times and locations at enrollment. However, there were several months between enrollment and the start of classes, so their availability may have changed. Furthermore, no prior studies have reported that offering education sessions in the evening is a barrier to attendance because they conflict with dinnertime. Given that participants reported a sense of community around shared food and a desire for longer sessions, future interventions of this nature may consider allocating more time to eat and providing meal-sized recipe portions.

Two additional recommendations to enhance education classes were offered by participants: offering each lesson more than once at different times and integrating childcare. The resource-intensive nature of these recommendations and limited funding and transportation for educational programmes in rural communities ${ }^{(24)}$ may impede their feasibility. Participants found it convenient to attend classes when they aligned with weekly CSA pick-ups. Such alignment may be the most efficient way to create convenience for participants, and the curriculum could be further refined to ensure engagement opportunities for children of diverse ages.

Given that lack of knowledge about $\mathrm{CSA}^{(18)}$, how they operate $^{(47)}$ and how to cook CSA produce ${ }^{(23)}$ are major barriers to CSA participation among low-income families, integrating nutrition and cooking education with cost-offset CSA access has potential for greater participant benefit. Participant-reported education class benefits, such as recipes and improved cooking behaviours, may have been facilitated by the accessibility and affordability of produce in CSA shares ${ }^{(36)}$ since access to produce are known barriers to healthy eating ${ }^{(48-50)}$ and behaviour change ${ }^{(51)}$ in lowincome families. Thus, researchers should continue to explore the feasibility and impact of interventions that combine food access with skill building and behaviour changesupporting education. However, lack of community and financial support has been a major barrier for health interventions in low-income and rural communities ${ }^{(24,52)}$. Therefore, online classes that do not require infrastructure or transportation may be more feasible.

Strengths of this study include the multi-site design, which allowed for a diverse sample of participant perspectives from four geographically diverse states. Standardised training of focus group facilitators aided in consistent data collection. Having multiple co-authors develop the codebook and double code the transcripts provided a wide perspective of the data and lent reliability and validity to the final codes and themes. Study limitations included poor focus group turnout. In 2016, 54\% of all F3HK participants 
attended focus groups, and, in 2017, $42 \%$ attended a focus group. This limited generalisability of our findings. Individuals who did not attend focus groups may have faced unique challenges to class attendance not captured in these focus groups. Additionally, although focus groups allowed for dialogue among participants, they limited our ability to analyse any relationship between individual and household characteristics, such as occupation or number of children, and reported benefits, barriers and recommendations. Lastly, the potential of social desirability and recall bias may have exaggerated perceived benefits of the intervention.

\section{Conclusion}

The CSA model is an alternative mode of accessing produce that has the potential to support fruit and vegetable consumption among low-income families. Participants believed that pairing nutrition education classes with a cost-offset CSA programme improved their own knowledge, food preparation skills and cooking habits, as well as knowledge, skills and habits of their children. Future interventions would benefit from better coordination with dynamic local growing cycles for maximal integration of unfamiliar CSA produce into lesson content. Coordinating classes with CSA pick-up and offering childcare may facilitate enrollment and retention in food access interventions that seek to incorporate locally sourced foods into family focused educational activities.

\section{Acknowledgements}

Acknowledgements: The authors thank Grace Marshall, Judy Ward and Brian Lo of Cornell University for their support of this work. Financial support: This research was supported by the National Institute of Food and Agriculture, U.S. Department of Agriculture (USDA), under award number 2015-68001-23230. USDA had no role in the design, analysis or writing of this article. Conflict of interest: None. Authorship: R.A.S., L.C.V., K.L.H., S.B.J.P., J.K., A.S.A., M.S. and I.L. conceived the study; R.A.S., J.K., E.H.B., M.S. and W.W. participated in data collection; I.L., L.G. and L. C.V. developed the coding approach; I.L. and L.G. coded all data; I.L., L.G., K.L.H. and S.B.J.P. analysed data and interpreted themes; all authors provided critical feedback on data analysis and interpretation and manuscript preparation. Ethics of human subject participation: This study was conducted according to the guidelines laid down in the Declaration of Helsinki, and all procedures involving human subjects were approved by the institutional review boards at the University of Vermont (CHRBS 16-393) and Cornell University (protocol ID \#1501005266). Written informed consent was obtained from all subjects.

\section{References}

1. Wang X, Ouyang Y, Liu J et al. (2014) Fruit and vegetable consumption and mortality from all causes, cardiovascular disease, and cancer: systematic review and dose-response meta-analysis of prospective cohort studies. BMJ 349, g4490-g4490.

2. Dauchet L, Amouyel P, Hercberg S et al. (2006) Fruit and vegetable consumption and risk of coronary heart disease: a meta-analysis of cohort studies. J Nutr 136, 2588-2593.

3. Farvid MS, Chen WY, Rosner BA et al. (2019) Fruit and vegetable consumption and breast cancer incidence: repeated measures over 30 years of follow-up. Int J Cancer 144, 1496-1510.

4. Ford ES \& Mokdad AH (2001) Fruit and vegetable consumption and diabetes mellitus incidence among U.S. adults. Prev Med (Baltim) 32, 33-39.

5. Wu Y, Zhang D, Jiang X et al. (2015) Fruit and vegetable consumption and risk of type 2 diabetes mellitus: a doseresponse meta-analysis of prospective cohort studies. Nutr Metab Cardiovasc Dis 25, 140-147.

6. Bellavia A, Larsson SC, Bottai M et al. (2013) Fruit and vegetable consumption and all-cause mortality : a dose-response analysis. Am J Clin Nutr 98, 11-14.

7. Lee-Kwan SH, Moore LV, Blanck HM et al. (2017) Disparities in state-specific adult fruit and vegetable consumption: United States, 2015. Morb Mortal Wkly Rep 66, 1241-1247.

8. Seligman HK, Laraia BA \& Kushel MB (2010) Food insecurity is associated with chronic disease among low-income NHANES participants. J Nutr 140, 304-310.

9. Banerjee S \& Radak T (2019) Association between food insecurity, cardiorenal syndrome and all-cause mortality among low-income adults. Nutr Health 25, 26010601 9869069.

10. Laz TH, Rahman M, Pohlmeier AM et al. (2015) Level of nutrition knowledge and its association with weight loss behaviors among low-income reproductive-age women. J Commun Health 40, 542-548.

11. Wolfson JA, Ramsing R, Richardson CR et al. (2019) Barriers to healthy food access: associations with household income and cooking behavior. Prev Med Rep 13, 298-305.

12. DeMuth S (1993) Commmunity Supported Agriculture (CSA): An Annotated Bibliography and Resource Guide. United States Department of Agriculture. https://pubs.nal.usda.gov/ sites/pubs.nal.usda.gov/files/at93-02_0.shtml (accessed May 2020).

13. Brown C \& Miller S (2008) The impacts of local markets: a review of research on farmers markets and community supported agriculture (CSA). Am J Agric Econ 90, 1296-1302.

14. Woods T, Ernst M \& Tropp D (2017) Community supported agriculture: new models for changing markets. https://www. ams.usda.gov/sites/default/files/media/CSANewModelsfor ChangingMarketsb.pdf (accessed December 2019).

15. United States Department of Agriculture (2016) Executive briefing: 2015 local food marketing practices survey. https://www.nass.usda.gov/Publications/AgCensus/2012/ Online_Resources/Local_Food/pdf/LocalFoodsBriefing Presentation_FINAL.pdf (accessed December 2019).

16. Jackson L \& Essl R (2008) Motivations for participating in community-supported agriculture and their relationship with community attachment and social capital. South Rural Sociol 23, 94-115.

17. Russell WS \& Zepeda L (2008) The adaptive consumer: shifting attitudes, behavior change and CSA membership renewal. Renew Agric Food Syst 23, 136-148.

18. Hanson KL, Garner J, Connor LM et al. (2019) Fruit and vegetable preferences and practices may hinder participation in community-supported agriculture among low-income rural families. J Nutr Educ Behav 51, 57-67. 
19. Cohen JN, Gearhart S \& Garland E (2012) Community supported agriculture: a commitment to a healthier diet. J Hunger Environ Nutr 7, 20-37.

20. Quandt SA, Dupuis J, Fish C et al. (2013) Feasibility of using a community-supported agriculture program to improve fruit and vegetable inventories and consumption in an underresourced urban community. Prev Chronic Dis 10, 130053.

21. Wilkins JL, Farrell TJ \& Rangarajan A (2015) Linking vegetable preferences, health and local food systems through community-supported agriculture. Public Health Nutr 18, 2392-2401.

22. Andreatta S, Rhyne M \& Dery N (2008) Lessons learned from advocating CSAs for low-income and food insuecure households. South Rural Sociol 23, 116-148.

23. Cotter EW, Teixeira C, Bontrager A et al. (2017) Low-income adults' perceptions of farmers' markets and communitysupported agriculture programmes. Public Health Nutr 20, $1452-1460$

24. Haynes-Maslow L, Osborne I \& Pitts SJ (2019) Examining barriers and facilitators to delivering SNAP-Ed direct nutrition education in rural communities. Am J Heal Promot 33, 736-744.

25. Wilkins JL \& Bokaer-Smith J (1996) Northeast Regional Food Guide. Media and Technology Services at Cornell University. https://ecommons.cornell.edu/bitstream/handle/1813/5085/ Northeast\%20Regional\%20Food\%20Guide.pdf (accessed January 2020).

26. New York State Department of Agriculture and Markets (2016) From A(pples) to Z(ucchini), your guide to New York's produce. https://agriculture.ny.gov/system/files/ documents/2019/03/harvestchart2016english.pdf (accessed January 2020).

27. Washington State Department of Agriculture Washington grown fruits, legume and herbs seasonality chart. https://agr. wa.gov/getmedia/497c614b-5c54-4277-89cf-4d6d1dd79c52/ seasonalitychartfruitlegumeherbsfinal.pdf (accessed January 2020).

28. Healthier US school challenge vegetable group (2010) Washington grown vegetable seasonality chart. https://agr. wa.gov/getmedia/00847f74-ac10-4622-a308-035f644552fc/ seasonalitycharthusscvegetablefinal.pdf (accessed January 2020).

29. North Carolina Department of Agriculture (2016) What's in season? North Carolina fruit and vegetable availability. http://www.ncagr.gov/markets/availabilitychart.pdf (accessed January 2020).

30. Bates R (2009) Specialty crops in North Carolina: acreage and distribution|NC State Extension Publications. https:// content.ces.ncsu.edu/specialty-crops-in-north-carolina-acreageand-distribution (accessed January 2020).

31. PickYourOwn.org (2020) Vermont crop harvest calendar: when fruit and vegetables are normally available and ready to pick in Vermont. https://www.pickyourown.org/ VTharvestcalendar.htm (accessed January 2020).

32. Hersch D, Perdue L, Ambroz T et al. (2014) The impact of cooking classes on food-related preferences, attitudes, and behaviors of school-aged children: a systematic review of the evidence, 2003-2014. Prev Chronic Dis 11, 1-10.

33. Reicks M, Trofholz AC, Stang JS et al. (2014) Impact of cooking and home food preparation interventions among adults: outcomes and implications for future programs. J Nutr EduC Behav 46, 259-276.

34. Seguin RA, Morgan EH, Hanson KL et al. (2017) Farm fresh foods for healthy kids (F3HK): an innovative community supported agriculture intervention to prevent childhood obesity in low-income families and strengthen local agricultural economies. BMC Public Health 17, 306.

35. Caspi CE, Sorensen G, Subramanian SV et al. (2012) The local food environment and diet: a systematic review. Heal Place 18, 1172-1187.

36. White MJ, Jilcott Pitts SB, McGuirt JT et al. (2018) The perceived influence of cost-offset community-supported agriculture on food access among low-income families. Public Health Nutr 21, 2866-2874.

37. Birmingham B, Shultz JA \& Edlefsen M (2004) Evaluation of a five-a-day recipe booklet for enhancing the use of fruits and vegetables in low-income households. J Community Health 29, 45-62.

38. Pooler JA, Morgan RE, Wong K et al. (2017) Cooking matters for adults improves food resource management skills and self-confidence among low-income participants. I Nutr Educ Behav 49, 545-553.e1.

39. Hersch D, Perdue L, Ambroz T et al. (2014) The impact of cooking classes on food-related preferences, attitudes, and behaviors of school-aged children: a systematic review of the evidence, 2003-2014. Prev Chronic Dis 11, 1-10.

40. Nikolaus CJ, Muzaffar H \& Nickols-Richardson SM (2016) Grocery store (or supermarket) tours as an effective nutrition education medium: a systematic review. J Nutr Educ Behav 48, 544-554.e1.

41. Jung SE, Shin YH, Niuh A et al. (2019) Grocery store tour education programme promotes fruit and vegetable consumption. Public Health Nutr 22, 2662-2669.

42. Jung SE, Shin YH, Niuh A et al. (2019) Grocery store tour education programme promotes fruit and vegetable consumption. Public Health Nutr 22, 2662-2669.

43. May JK, Brady A, Van Offelen S et al. (2014) Simply good cooking: online curriculum for the interactive SNAP-Ed classroom. J Nutr Educ Behav 46, 85-87.

44. Dunbar RIM (2017) Breaking bread: the functions of social eating. Adapt Hum Behav Physiol 3, 198-211.

45. Dannefer R, Abrami A, Rapoport R et al. (2015) A mixedmethods evaluation of a SNAP-Ed farmers' market-based nutrition education program. J Nutr Educ Behav 47, 516-525.e1.

46. Slusser W, Prelip M, Kinsler J et al. (2011) Challenges to parent nutrition education: a qualitative study of parents of urban children attending low-income schools. Public Health Nutr 14, 1833-1841.

47. Cotter EW, Teixeira C, Bontrager A et al. (2017) Short communication low-income adults' perceptions of farmers' markets and community-supported agriculture programmes. Public Health Nutr 20, 1452-1460.

48. Eikenberry N \& Smith C (2004) Healthful eating: perceptions, motivations, barriers, and promoters in low-income Minnesota communities. I Am Diet Assoc 104, 1158-1161.

49. Cassady D, Jetter KM \& Culp J (2007) Is price a barrier to eating more fruits and vegetables for low-income families? $\mathrm{J} \mathrm{Am}$ Diet Assoc 107, 1909-1915.

50. Pollard J, Kirk SFL \& Cade JE (2002) Factors affecting food choice in relation to fruit and vegetable intake: a review. Nutr Res Rev 15, 373-387.

51. John JH (2004) Reported barriers to eating more fruit and vegetables before and after participation in a randomized controlled trial: a qualitative study. Health Educ Res 19, 165-174.

52. Barnidge EK, Radvanyi C, Duggan K et al. (2013) Understanding and addressing barriers to implementation of environmental and policy interventions to support physical activity and healthy eating in rural communities. J Rural Health 29, 97-105. 